\title{
Assessment of blood flow patterns in the pulmonary artery using 4D flow
}

\author{
Pablo Bächler ${ }^{1 *}$, Natalia Pinochet ${ }^{1}$, Cristián Tejos ${ }^{1}$, Crelier Gerard² ${ }^{2}$ Pablo Irrarázabal', Sergio Uribe ${ }^{1}$ \\ From 2011 SCMR/Euro CMR Joint Scientific Sessions \\ Nice, France. 3-6 February 2011
}

\section{Background}

4D Flow has been used to study flow patterns, mainly in the aorta. In the Pulmonary Artery (PA) an abnormal Vortex (VO) has been described in association with pulmonary hypertension [1]. However, a systematic analysis of flow patterns in the PA has not been performed.

\section{Objective}

To perform hemodinynamic analysis in the PA in volunteers and patients with CHD after Glenn procedure.

\section{Methods}

Eighteen volunteers and two patients underwent 4D Flow scan on a Phillips system (25 frames, $\left.2.5 \mathrm{~mm}^{3}\right)$. Flow was visualized by streamlines and particle traces ("GTFlow" software). 2D planes placed in 5 locations were used to grade flow patterns: 1) just after to the pulmonary valve, 2) before the PA bifurcation, 3) between plane 1 and 2, 4) Right-PA, and 5) Left-PA. Sagital and coronal planes were also analyzed. VOs that lasted at least 2 frames were registered (start, finish and peak-frame; direction, size, and distance between vortexcenter and vessel-center).

\section{Results}

Two VOs were identified in the PA in volunteers (Fig. 1a). $\mathrm{VO}_{1}$ was seen in all volunteers and $\mathrm{VO}_{2}$ in sixteen. Both vortices started at peak-systole and ended at late-systole. $\mathrm{VO}_{1}$ was located on posterior wall and $\mathrm{VO}_{2}$ on anterior wall, with clockwise and counterclockwise direction respectively. $\mathrm{VO}_{1}$ was smaller compared with $\mathrm{VO}_{2}(24 \% \pm 7 \%$ of vessel area vs. $31 \% \pm 7 \%$, pvalue $=0.03) . \mathrm{VO}_{1}$ 's center was located closer to the vessel's center compared with $\mathrm{VO}_{2}$ 's center $(10.1 \mathrm{~mm} \pm$ $2 \mathrm{~mm}$ vs. $11.4 \mathrm{~mm} \pm 2 \mathrm{~mm}$, p-value $=0.02)$. A clockwise

${ }^{1}$ Pontificia Universidad Católica de Chile, Santiago, Chile

Full list of author information is available at the end of the article
VO was also seen in Right-PA in 15 volunteers (Fig. 1b), starting at peak-systole and ending at early-diastole. VO's size was on average $51 \% \pm 20 \%$ of Right-PA area.

In both patients abnormal VOs were detected. At systole a VO in PA associated to backward flow was found (Fig. 1c). A main finding was retrograde blood flow from superior vein cava (SVC) at diastole, showing that up to $90 \%$ (in one frame) of SVC flow goes toward proximal Right-PA, and more than $70 \%$ reaches to the main PA (Fig. 1d).

\section{Conclusion}

VOs are normally founded in PA in healthy subjects. Abnormal blood flow patterns are seen in the PA in patients after Gleen procedure, with most of flow from SVC going to the main PA and right ventricle.

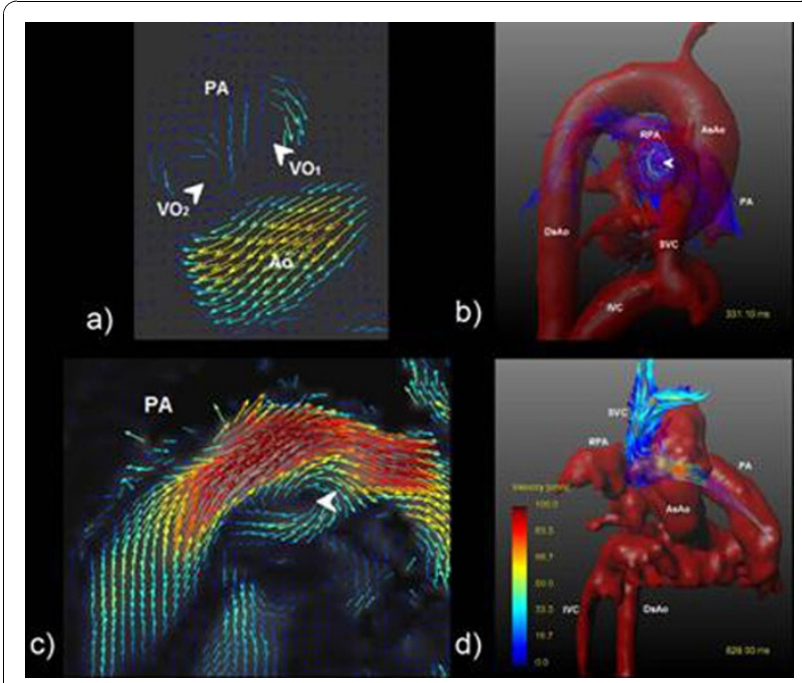

Figure 1 a) and b) Vortices in the PA and Right-PA seen in volunteers. c) Retrograde flow seen in the PA of patients. d)Flow from the SVC to the PA and right ventricle. 


\section{Author details}

${ }^{1}$ Pontificia Universidad Católica de Chile, Santiago, Chile. ${ }^{2}$ Institute for

Biomedical Engineering, University and ETH., Zurich, Switzerland.

Published: 2 February 2011

\section{Reference}

1. Reiter $G$, et al: 2008 .

doi:10.1186/1532-429X-13-S1-P66

Cite this article as: Bächler et al:: Assessment of blood flow patterns in

the pulmonary artery using 4D flow. Journal of Cardiovascular Magnetic

Resonance 2011 13(Suppl 1):P66.

Submit your next manuscript to BioMed Central and take full advantage of:

- Convenient online submission

- Thorough peer review

- No space constraints or color figure charges

- Immediate publication on acceptance

- Inclusion in PubMed, CAS, Scopus and Google Scholar

- Research which is freely available for redistribution 